\title{
ODE À LÍVIA DE OLIVEIRA!
}

Lúcia Helena Batista GRATÃO ${ }^{1}$

Antes de me acomodar à mesa para nos servirmos de "Uma Geografia Afetiva: Literatura e Sabores Geográficos”2, permitam-me estender algumas palavras à nossa Homenageada, Lívia de Oliveira. Palavras de louvação! Louvação a esta mulher encantada pela geografia e, pela vida! Uma mulher encantada pelo Mundo!

A este enlevo, preparei esta composição lírico-poética que desejaria fosse lida com acompanhamento da viola caipira como uma ode à Lívia de Oliveira! Ode, como uma louvação ou um elogio lírico; palavras lidas, não cantadas; nem poema, mas, como expressão poética a uma figura louvada, exaltada! Expressão poética para agradecer os afetos, a estimação, o apreço; aplausos à dedicação de ensinar e de apreciar com tanto gosto os saberes e sabores geográficos; a apreciação dos ensaios com rigor, afetividade e amizade; o desvelo na orientação e o primor da escrita; a dedicação ao que faz; o discernimento diante do que expõe a vida!

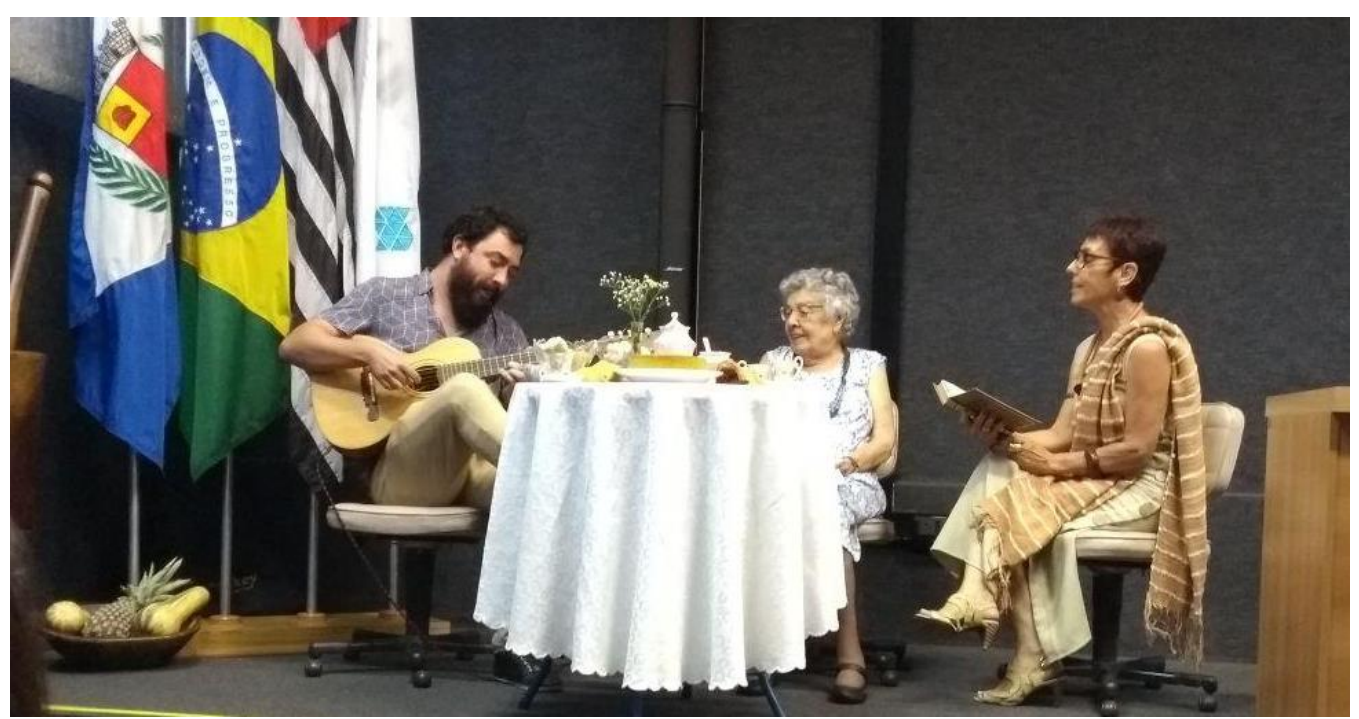

Homenagem aos 90 anos de Lívia de Oliveira, durante a abertura do VIII SEGHUM, realizado na UNESP, em Rio Claro. Henrique Pazetti dedilha sua viola caipira à medida que Lúcia Helena declama esta Ode (2017).

\footnotetext{
${ }^{1}$ Professora-Adjunta do Departamento de Geociências da Universidade Estadual de Londrina UEL. E-mail: aguasdelu@yahoo.com.br.

2 Mesa-redonda do VIII Seminário Nacional sobre Geografia e Fenomenologia: "Lívia de Oliveira faz 90 anos" (VII SEGHUM)), em 2017, realizado na Universidade Estadual Paulista, campus de Rio Claro.
} 
Por tudo isso, louvo e preconizo a sua rica contribuição para a geografia em atitude de exaltação ao vigor, jovialidade e longevidade! Aclamada Mestra e Amiga, Lívia! Gratidão!

Os encontros com Lívia foram sempre permeados e entoados por animadas conversas em torno de sabores experimentados, experienciados, provados e degustados pelos tantos lugares por onde andou... por onde viajou... Foram muitas viagens, muitos lugares: Estados Unidos, Canadá, França, Marrocos e, tantos cantos e recantos por este Brasil e Mundo afora. Quantos lugares viajados e saboreados pelos saberes da geografia e seus sabores. Quando falava do que comeu, da comida do lugar visitado e degustado, era uma verdadeira aula de geografia do sabor, narrada com todos os detalhes do lugar, da paisagem, do plantio, do cultivo, da colheita - do alimento à mesa -; a preparação do prato na composição dos alimentos, ingredientes e temperos até chegar à mesa, e, ainda, os modos e maneiras de servir - e até de sentar.

Encontros embalados pelo encantamento da geografia com suas paisagens e seus lugares impregnados de sabores. Encontros saborosos entrelaçados por afeto! Doce afeto! Encontros e conversas entoadas por fortes notas em andante e allegro. Ode à alegria!

Nesse embalar de conversas, geografias afetivas iam brotando como brotam as árvores para o (en)canto dos passarinhos, como o encanto manifesto por Lívia pelos passarinhos, registro afetivo que sempre surgia ao falarmos da Natureza. Esta Natureza-Terra tão louvada, tão amada por ela! E, aqui me lembro do seu encantamento pelo ipê florido. Ah, se eu tivesse o dom de cantar, cantaria ao dedilhar das cordas da viola caipira, uma canção com belos versos e, assim, acalentar o coração e a alma enlevada pelo carinho e admiração pelas suas belas geografias que nos embala e nos embevece de profundo afeto.

Ah, e os deliciosos cafés saboreados em tantos lugares - aqui, ali, acolá Londrina, Rio Claro, Niterói, Petrópolis, Maricá, Campinas, Limeira, Belo Horizonte, Ilhéus, Goiânia, Trindade, Goiás Velho! Ah, quantos lugares visitados juntas! Quantos sabores compartilhados! E os doces deliciosos servidos pelas suas mãos de professora, degustados à mesa no seu apartamento, por entre tantos livros, lembranças de viagens e presentes de ex-alunos e muita alegria! Ode à alegria! 
Quanto aprendizado de saberes e sabores geográficos - percepção geográfica, topofilia, meio ambiente, cartografia, didática, geomorfologia, climatologia, hidrologia (me deu de presente suas pastas de aula, puro orgulho e honra; sim, Lívia ministrou aulas de hidrologia). Quantos outros - literatura, viagens, geografia humanista (pioneira), e, claro, geografia do sabor.

A esta mistura de saberes pelo maravilhoso campo da geografia com seus muitos meridianos e paralelos, tempos, climas, paisagens, lugares, mesas de cafés, foi se desvelando o nosso interesse comum pelo sabor. E, aí, brota mais um encantamento pelo campo da geografia (mesmo que ensinando Geografia Física - Hidrografia). Foi quando Lívia, estando em Londrina, em 2010 e, em torno de uma mesa preparada com muito apreço para recebê-la, conversamos longamente sobre o meu desejo de desenvolver uma pesquisa em torno do sabor em geografia. Logo em seguida, fomos até a Rádio FM da UEL para uma entrevista, e, inusitadamente Lívia anunciava o meu desejo e, assim foi ao ar o meu sonho, agora, revelado.

Lívia voltou para Rio Claro, e eu, ao ritmo das atividades acadêmicas, pensando, imaginando fui sendo embalada pelo sonho revelado, até que numa tarde inesperada depois de ter voltado recentemente de uma atividade em Rio Claro, fui arrebatada pela chegada de uma correspondência de Lívia. Mãos trêmulas pela surpresa, abri o envelope e era uma carta (escrita à mão). Comecei a ler e logo vi que assim estava escrito: se eu quisesse fazer o pós-doutorado com ela sobre sabor, me aceitaria. E, agora, não só com as mãos trêmulas, mas o coração pululando, palpitava! Uma mistura de alegria, contentamento, felicidade, mas, ao mesmo tempo, perturbada pela ideia. Pensei comigo, fazer o pós-doc com Lívia de Oliveira em Rio Claro! É isso mesmo? Sim, é isso mesmo que está escrito nessas linhas manuscritas por Lívia? Era isso mesmo! Um novo vislumbre! Mais um novo desafio! Mais uma nova ousadia! Memórias de muitas décadas passadas reviveram e reviraram em mim. Alegria, contentamento, responsabilidade e tantos outros ingredientes, temperos e essências se misturavam num só sabor!

E aqui vim! Aqui fiz o pós-doutorado sobre o sabor em geografia sob a supervisão de Lívia de Oliveira. Aqui estou para servir a esta nova mesa com a mais profunda gratidão! 


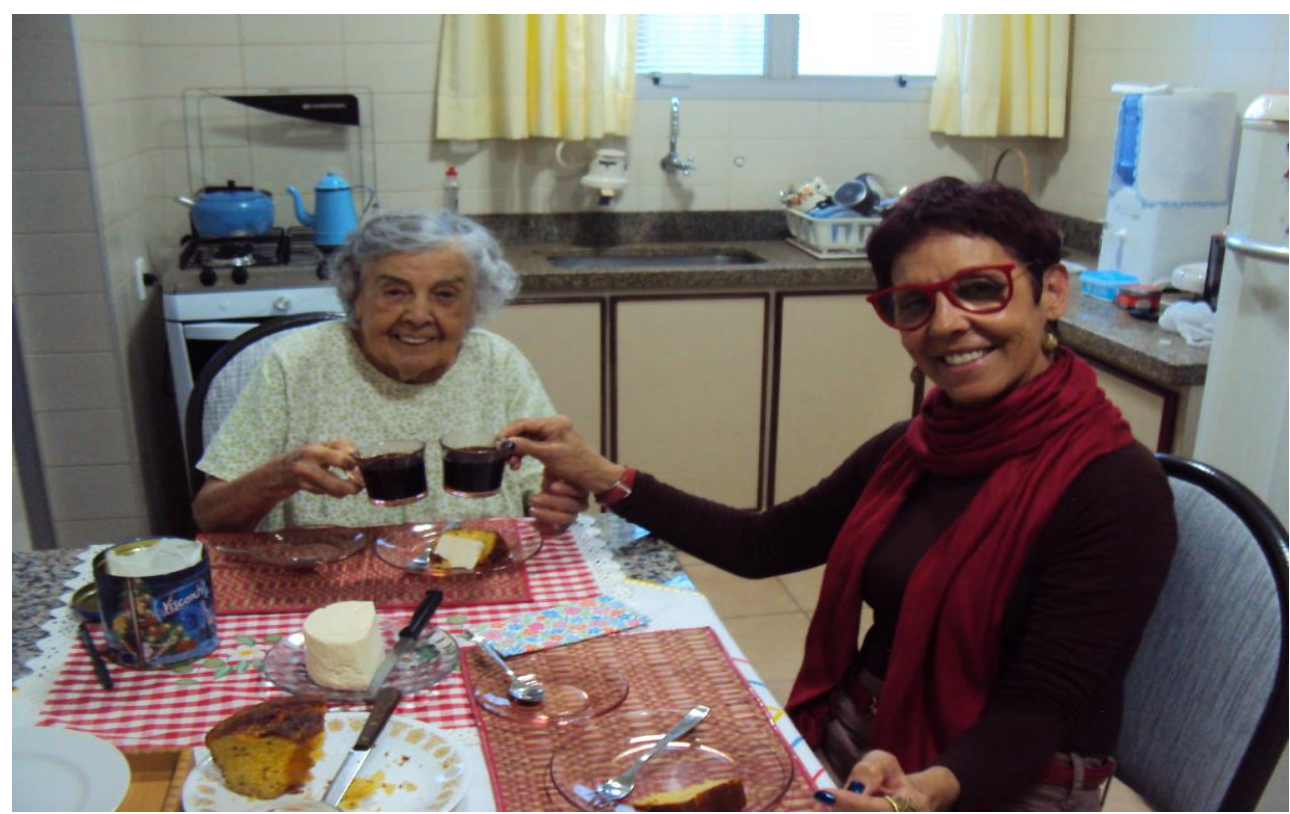

Lívia recebe Lúcia Helena para um café em seu apartamento, em Rio Claro (2016).

Lívia, mulher forte, corajosa, determinada, ousada e, ao mesmo tempo, sensível; acolhedora de frutos e afetos; carinhosa! Dura e afetuosa num só ato de ensinar e de servir à mesa. Uma primorosa comensal no seu mais puro sentido.

Que história de Vida! Que memórias de vida! Que sensibilidade de viver e existir!

Lívia, história de encantamento pela geografia e pela vida. Vida embevecida de vigor. Vida que embevece o nosso coração geográfico.

Lívia, obrigada por todo esse encantar de mundo que nos enleva ao fazer geográfico, cada dia mais, com o coração e com a alma; fonte de inspiração, entusiasmo, ousadia.

Obrigada pelos ensinamentos afetuosos.

Obrigada pela sua geografia afetiva.

Obrigada por esta geografia que por ela aqui estou a exalar-exaltar!

Gratidão!

Rio Claro, tarde de 16 de novembro de 2017!

Enviado em 25 de agosto de 2020 